\title{
Minimally Invasive Open Reduction by a Modified Suture Bridge with Anchors for Avulsion-type Greater Tuberosity Fracture of the Humerus
}

\author{
Lingpeng Kong \\ Shandong Provincial Hospital https://orcid.org/0000-0003-4809-6825 \\ Juanjuan Yang \\ Shandong Cancer Hospital: Shandong Cancer Hospital and Institute \\ Yongliang Yang \\ Shandong Provincial Hospital \\ Fu Wang ( $\checkmark$ wangfu197286@163.com ) \\ Shandong Provincial Hospital Affiliated to Shandong First Medical University https://orcid.org/0000-0001-7641-3475
}

Technical note

Keywords: Minimally invasive, greater tuberosity fracture, open reduction, suture bridge, anchor

Posted Date: February 9th, 2021

DOI: https://doi.org/10.21203/rs.3.rs-157724/v2

License: (c) (1) This work is licensed under a Creative Commons Attribution 4.0 International License. Read Full License 


\section{Abstract}

Background: This study aims to describe a new procedure of minimally invasive open reduction by a modified suture bridge with anchors for avulsion-type greater tuberosity fracture of the humerus and to evaluate its clinical effectiveness.

Methods: From January 2015 to January 2018, 16 patients who were diagnosed with an avulsion-type greater tuberosity fracture of the proximal humerus and treated with minimally invasive open reduction by modified suture bridges with anchors were retrospectively studied. Endpoints were assessed preoperatively and postoperatively and included the visual analog scale (VAS), the University of California Los Angeles (UCLA) shoulders score, the American Shoulder and Elbow Surgeons score (ASES), and the range of motion (ROM) for shoulders.

Results: There were 7 males and 9 females with an average age of 44.94 years. Six fractures involved the left shoulder, and 10 involved the right shoulder. The time between injury and operation ranged from 1 to 5 days, with an average of 2.32 days. The average length of stay was $6.5 \pm 0.85$ days; the mean operation time was $103.1 \pm 7.23$ minutes; and the mean amount of operative blood loss was $51.88 \pm 6.40 \mathrm{ml}$. All patients achieved bone union within 3 months after surgery. The VAS score significantly decreased at 3 weeks postoperatively $(p=0.002)$, as did the average degree of forward elevation $(p=0.047)$. The mean degree of abduction increased at 6 weeks after the operation $(p=0.035)$, and the average degree of external rotation and internal rotation improved at 3 months postoperatively $(p=0.012 ; p=0.007)$. The ASES score and the UCLA score improved at the 6-week follow-up ( $p=0.092 ; p=0.029)$. No procedure-related death or incision-related superficial or deep tissue infection was identified in any case. No iatrogenic neurovascular injuries or fractures were found in this study.

Conclusion: The fracture block was fixed firmly by minimally invasive open reduction with a modified suture bridge with anchors. Patients were allowed to move their shoulder early after surgery and recovered quickly. It is an efficient method for the treatment of avulsion-type greater tuberosity fractures of the humerus.

\section{Introduction}

Proximal humerus fractures are the most common injuries, accounting for approximately $5 \%$ of total body fractures [1]. Greater tuberosity fractures, as a very special type of proximal humeral fracture, account for approximately $20 \%$ of proximal humeral fractures [2,3] and are often accompanied by different degrees of rotator cuff injury because the humeral greater tubercle is the attachment point of the rotator cuff, which often pulls the fractured fragments to separate and shift after avulsion.

The treatment for this type of fracture can be classified into conservative and surgical strategies. The former uses a shoulder pillow or brace in an abduction position, with poor prognosis [4], often resulting in shoulder joint pain, movement limitation, acromion impingement, limb weakness and other functional disorders [5]. Although the surgical indication for fractures of the humeral greater tubercle is still controversial, most surgeons suggest that if the fracture displacement is more than $5 \mathrm{~mm}$, surgical treatment will be recommended [6]. At present, the main surgical procedures for simple avulsion fractures of the humeral greater tubercle are screw fixation, suture anchor fixation, and plate fixation [3]. Among them, open reduction and internal fixation with plates is widely used, but several problems, such as a larger incision, more damage to blood circulation and periosteum, influence on fracture healing, and acromion impingement will be encountered [7]. Compared with conventional plates, locking plates bring important changes in fracture management, allowing flexible biological fracture fixation based on the principle of internal fixators and reducing the incidence of failed bone healing [8, 9]. However, several studies have shown a higher than expected incidence of plate fixation complications associated with ischemic necrosis, delayed healing, malunion, nonunion, and implant failure $[10,11]$. In particular, the incidence of screw-related mechanical complications, such as screw perforation, cutoff, screw rotation, and loosening, should not be overlooked [12]. Cannulated screws and washers in the treatment of humeral greater tubercle fractures have the advantages of simple procedures and short operation times, as well as firm fixation of bone mass, but the incidence of postoperative stiffness and pain is higher [13], and these are not suitable in osteoporosis patients because the bone of the greater tubercle tends to be fragile and prone to further commination [14].

The technique of double-row anchor suture under arthroscopy is expensive and complicated to perform. In addition, as a postoperative complication, inadequate reduction can lead to postoperative stiffness due to the difficulty of adequate reduction 
and fixation of severely displaced fracture fragments with wire anchors [15]. To reduce surgical complications and provide better treatment for patients, we have been inspired by the repair of rotator cuff injuries using the suture bridge technique to fix fractures of the great tubercle of the humerus through a minimally invasive small incision under direct vision.

The purposes of this study were to 1) present a new, minimally invasive surgical technique for the treatment of avulsion fractures of the greater tuberosity of the humerus and 2) evaluate the clinical outcomes of 16 patients, including restoration of work activity, ROM and strength, and patient-based function.

\section{Materials And Methods Study population}

Inclusion criteria were as follows: 1) X-ray, CT (computed tomography) or MRI(Magnetic Resonance Imaging)of the shoulder showing avulsion fracture of the greater tuberosity, assessed according to the classification system of Mutch et al. [16]; 2) fracture displacement between $5 \mathrm{~mm}$ and $10 \mathrm{~mm}$; 3) closed fracture; 4) fresh fractures (no more than 3 weeks after surgery); 5) all cases followed up for more than 1 year.

The exclusion criteria were as follows: 1) split fracture and compressed fracture of the humeral greater tubercle; 2) fracture of the humeral greater tubercle associated with proximal humerus fracture; 3) shoulder joint dysfunction before admission; and 4) greater tubercle fracture of the humerus combined with brachial plexus injury.

Between January 2015 and January 2018, 16 patients with avulsion fractures of the humeral greater tuberosity were referred to our hospital. There were 7 males and 9 females, with an average age of 44.94 years (range, 20-65 years). The mechanism of injury was falls in 9 patients, traffic accident injuries in 4 patients, and crash injuries in 3 patients. Six fractures involved the left shoulder, and 10 involved the right shoulder. The time between injury and operation ranged from 1 to 5 days, with an average of 2.32 days. There were 7 patients with other diseases. One patient had a right clavicle fracture, 1 patient had a left tibia and fibula fracture, and 1 patient had a left radius fracture. The patients' demographic data are listed in Table 1. 
Table 1

The patients' demographic data

\begin{tabular}{|c|c|c|c|c|c|c|c|c|c|c|c|}
\hline \multirow[t]{2}{*}{ Patients } & \multirow[t]{2}{*}{ Sex } & \multirow[t]{2}{*}{ Age } & \multirow[t]{2}{*}{ MBI } & \multicolumn{4}{|c|}{ Complications } & \multirow[t]{2}{*}{ Other fractures } & \multirow[t]{2}{*}{ Inducement } & \multirow[t]{2}{*}{ Side } & \multirow{2}{*}{$\begin{array}{l}\text { Time } \\
\text { between } \\
\text { injury and } \\
\text { operation }\end{array}$} \\
\hline & & & & HBP & $\mathrm{DM}$ & CHD & Others & & & & \\
\hline 1 & $\mathrm{~F}$ & 63 & 22.86 & No & No & No & COPD & No & fall injury & $\mathrm{R}$ & 1 \\
\hline 2 & $\mathrm{~F}$ & 52 & 27.66 & No & No & No & No & No & fall injury & $\mathrm{L}$ & 2 \\
\hline 3 & $\mathrm{~F}$ & 62 & 20.57 & Yes & Yes & No & No & $\begin{array}{l}\text { Right clavicle } \\
\text { fracture }\end{array}$ & crash injury & $\mathrm{R}$ & 2 \\
\hline 4 & $M$ & 25 & 23.62 & No & No & No & No & No & $\begin{array}{l}\text { traffic } \\
\text { accident }\end{array}$ & $\mathrm{L}$ & 2 \\
\hline 5 & $M$ & 50 & 22.65 & No & No & Yes & CVA & No & crash injury & $\mathrm{L}$ & 1 \\
\hline 6 & M & 44 & 20.33 & Yes & No & No & No & No & fall injury & $\mathrm{L}$ & 2 \\
\hline 7 & $M$ & 49 & 23.95 & No & No & No & No & No & fall injury & $\mathrm{R}$ & 2 \\
\hline 8 & $\mathrm{~F}$ & 28 & 22.87 & No & No & No & No & No & fall injury & $\mathrm{R}$ & 2 \\
\hline 9 & $\mathrm{~F}$ & 30 & 25.69 & No & No & No & No & No & fall injury & $\mathrm{R}$ & 2 \\
\hline 10 & $\mathrm{~F}$ & 46 & 21.61 & No & No & No & No & No & fall injury & $\mathrm{L}$ & 4 \\
\hline 11 & $M$ & 53 & 23.69 & No & Yes & No & No & No & $\begin{array}{l}\text { traffic } \\
\text { accident }\end{array}$ & $\mathrm{R}$ & 2 \\
\hline 12 & $M$ & 20 & 26.33 & No & No & No & No & $\begin{array}{l}\text { Left tibia and } \\
\text { fibula fracture }\end{array}$ & $\begin{array}{l}\text { traffic } \\
\text { accident }\end{array}$ & $\mathrm{L}$ & 5 \\
\hline 13 & $\mathrm{~F}$ & 30 & 28.57 & No & No & No & No & No & crash injury & $\mathrm{R}$ & 2 \\
\hline 14 & $\mathrm{~F}$ & 65 & 21.50 & No & No & No & No & No & $\begin{array}{l}\text { traffic } \\
\text { accident }\end{array}$ & $\mathrm{R}$ & 1 \\
\hline 15 & $M$ & 41 & 28.78 & No & No & No & $\mathrm{HCV}$ & No & fall injury & $\mathrm{R}$ & 2 \\
\hline 16 & $\mathrm{~F}$ & 61 & 29.33 & Yes & No & No & No & $\begin{array}{l}\text { Left radius } \\
\text { fracture }\end{array}$ & fall injury & $\mathrm{R}$ & 5 \\
\hline
\end{tabular}

\section{Radiologic assessment}

For radiologic evaluation, avulsion fractures of the humeral greater tuberosity were diagnosed preoperatively by X-ray (Fig. 1A), planar CT scan (Fig. 1B), coronal CT scan (Fig. 1C), and three-dimensional reconstruction image (Fig. 1D) of the humerus. The height and width of the fracture fragments and the fracture displacement were assessed with three-dimensional CT scans. The height and width of the fracture fragments were $22.69 \pm 1.88 \mathrm{~mm}$ (range, 10-33 mm) and 16.94 $\pm 1.71 \mathrm{~mm}$ (range, 8-26 mm), respectively, with an average displacement of $19.75 \pm 2.05 \mathrm{~mm}$ (range, $5-30 \mathrm{~mm}$ ) (Table 2). 
Table 2

The data of fragments and intraoperative

\begin{tabular}{|c|c|c|c|c|c|c|}
\hline Patients & $\begin{array}{l}\text { Height } \\
\text { of the fragments } \\
(\mathrm{mm})\end{array}$ & $\begin{array}{l}\text { Width of the } \\
\text { fragments (mm) }\end{array}$ & $\begin{array}{l}\text { Displacement } \\
(\mathrm{mm})\end{array}$ & $\begin{array}{l}\text { Operative } \\
\text { time (min) }\end{array}$ & $\begin{array}{l}\text { Bleeding } \\
\text { volume }(\mathrm{mL})\end{array}$ & $\begin{array}{l}\text { Length of } \\
\text { stay (day) }\end{array}$ \\
\hline 1 & 15 & 25 & 10 & 2 & 100 & 4 \\
\hline 2 & 20 & 19 & 15 & 1 & 50 & 4 \\
\hline 3 & 30 & 8 & 5 & 1.5 & 50 & 4 \\
\hline 4 & 10 & 26 & 20 & 1.5 & 30 & 6 \\
\hline 5 & 33 & 8 & 30 & 1.5 & 30 & 5 \\
\hline 6 & 25 & 10 & 16 & 3 & 30 & 4 \\
\hline 7 & 17 & 19 & 20 & 1 & 50 & 5 \\
\hline 8 & 33 & 9 & 15 & 2.5 & 100 & 6 \\
\hline 9 & 26 & 15 & 30 & 2 & 50 & 6 \\
\hline 10 & 30 & 10 & 26 & 2 & 30 & 15 \\
\hline 11 & 19 & 22 & 30 & 2 & 50 & 14 \\
\hline 12 & 20 & 24 & 8 & 2 & 100 & 9 \\
\hline 13 & 28 & 15 & 25 & 2 & 50 & 6 \\
\hline 14 & 16 & 23 & 14 & 1.5 & 30 & 5 \\
\hline 15 & 12 & 26 & 24 & 1 & 50 & 7 \\
\hline 16 & 29 & 12 & 28 & 1.5 & 30 & 4 \\
\hline
\end{tabular}

\section{Operative procedures}

The operation was performed under general anesthesia in a $20^{\circ}$ beach chair position. A $3 \mathrm{~cm}$ longitudinal skin incision was made from the anterolateral angle of the acromion. The deltoid muscle was dissected bluntly to expose the subacromial bursa. Supraspinatus and infraspinatus muscle avulsion fractures, great tubercle area fractures, multiple fracture fragments and rotator cuff lacerations were observed (Fig. 2A). The broken end of the bone was then cleaned, and the free bone fragments were removed. Two $5.0 \mathrm{~mm}$ anchors were inserted into the cartilaginous margin of the humeral head, and then the anchor lines were passed through the rotator cuff tissue and knotted (Fig. 2B). Kirschner wire was used for temporary fixation of the greater tubercle fracture fragments, and a hole of appropriate length was drilled at the distal outer edge of the fracture line at approximately $5-10 \mathrm{~mm}$, according to the size of the fracture fragment. The large tubercle fracture was reduced and fixed by the suture bridge technique, and the torn rotator cuff tissue was repaired. Intraoperative fluoroscopy showed the position of the anchors and the reduction of the fracture (Fig. 2C). Figure 3 shows a schematic diagram of the main points of the surgical procedure.

\section{Postoperative rehabilitation}

Ice was applied 1-2 days after the operation to relieve pain and swelling of the incision. The patients were encouraged to walk on the ground, and the arm was immobilized with a shoulder abduction brace in a neutral position to prevent internal rotation. The patients began to carry out passive rehabilitation training under the guidance of rehabilitation doctors $3-5$ days postoperatively, according to the patient's specific situation, and continued passive function exercise up to 1-4 weeks after 
surgery. The external fixator was removed 5 weeks postoperatively, and the amount of motion was increased under the guidance of the rehabilitation physician. The patients began to perform active shoulder joint exercise 6 weeks postoperatively.

\section{Functional assessment}

Visual analog scale (VAS) for pain assessment, American Shoulder and Elbow Surgeon (ASES) Score, University of California Los Angeles (UCLA) Shoulder score, and ROM of the joint were used to assess the function of the affected shoulder joint. Active joint range of motion is measured based on the forward flexion of the scapula plane and the external and internal rotation of the lateral arm. Internal rotation is estimated by determining the highest spinal segment the patient can reach with the thumb. For ease of statistical analysis, spinal segments were converted into numbers: segments T1 through T12 were designated as 1 through 12, segments L1 through L5 were designated as 13 through 17, and the sacrum was designated as 18 [17, 18]. The pain scale, shoulder function score, and active ROM were assessed by an independent reviewer.

\section{Statistical analysis}

IBM 20.0 statistical software (International Business Machines Corporation, Ar. monk, New York, USA) was used for statistical analysis. Parametric data, such as VAS, ASES and UCLA scores, are described as the mean \pm SEM and were compared using Student's $t$-tests. Proportional values were compared using $\chi^{2}$ analysis or Fisher's exact test where applicable. For each test, a $P$ value $<0.05$ was defined as significant.

\section{Results}

\section{Operative records and Complications}

As shown in Table 2, the average length of stay was $6.5 \pm 0.85$ days (range, $4-15$ days); the mean operation time was $103.1 \pm$ 7.23 minutes (range, 60-150 minutes); and the mean amount of operative blood loss was $51.88 \pm 6.40 \mathrm{ml}$ (range, 30-100 ml). 1 day after operation, the radiography and CT demonstrated a good reduction in the greater tuberosity (Fig. 4A, 4B, 4C), and the fracture has healed 1 months after surgery (Fig. 4D). None of the patients developed superficial or deep infections in the surgical site, and there were no wound healing problems in any patients. No sensory loss in the upper arm or shoulder associated with the axillary nerve or displacement was observed among patients in this group during the surveillance period. No procedure-related death was observed in any case.

\section{Functional and radiologic outcomes}

All patients were followed up with clinical examination and radiographs at 3 weeks, 6 weeks, 3 months, 6 months and 12 months after surgery and then every 6 months (Table 3 ). The mean follow-up time was $16.31 \pm 1.01$ months (range, 12-24 months). Plain radiographs or CT scans demonstrated that 16 cases had solid fusion 3 months after surgery. At the time of follow-up, the forward elevation was significantly improved at 3 weeks, from $65.63 \pm 1.82^{\circ}$ preoperatively to $71.88 \pm 2.41^{\circ}$ postoperatively $(p=0.047)$. The average degree of external rotation improved from $9.38 \pm 1.93^{\circ}$ preoperatively to $15 \pm 2.19^{\circ}$ at 3 months postoperatively $(p=0.012)$. The mean degree of internal rotation improved from $17.56 \pm 0.16^{\circ}$ preoperatively to $16.81 \pm$ $0.21^{\circ}$ at 3 months postoperatively $(p=0.007)$. The mean degree of abduction increased from $48.13 \pm 2.09^{\circ}$ to $56.88 \pm 3.38^{\circ}$ at 6 weeks after the operation $(p=0.035)$. The average VAS score significantly decreased from $6.19 \pm 0.21$ points preoperatively to $5.19 \pm 0.21$ at 3 weeks postoperatively $(p=0.002)$. The ASES score was significantly improved at 6 weeks, from $38.69 \pm 2.03$ points to $43.56 \pm 1.93$ points $(p=0.092)$. The mean UCLA score improved from $9.94 \pm 0.52$ points to $11.5 \pm 0.44$ points at the 6week follow-up $(p=0.029)$. The mean VAS score measured at 12 months postoperatively was $0.63 \pm 0.22$; UCLA score was $29.75 \pm 0.90$; and ASES score was $89.81 \pm 1.69$. The mean active forward flexion, external rotation, abduction and internal rotation of vertebral levels were $138.1 \pm 2.23^{\circ}, 33.44 \pm 2.53^{\circ}, 140.6 \pm 3.35^{\circ}$ and $13.31 \pm 0.25$, respectively. 
Table 3

Postoperative outcome of patients

\begin{tabular}{|c|c|c|c|c|c|c|}
\hline $\begin{array}{l}\text { Evaluation } \\
\text { items }\end{array}$ & Preoperative & $\begin{array}{l}3 \text { weeks } \\
\text { postoperatively }\end{array}$ & $\begin{array}{l}6 \text { weeks } \\
\text { postoperatively }\end{array}$ & $\begin{array}{l}3 \text { months } \\
\text { postoperatively }\end{array}$ & $\begin{array}{l}6 \text { months } \\
\text { postoperatively }\end{array}$ & $\begin{array}{l}12 \text { months } \\
\text { postoperatively }\end{array}$ \\
\hline VAS & $6.19 \pm 0.21$ & $5.19 \pm 0.21$ * & $3.81 \pm 0.16^{\star}$ & $2.38 \pm 0.20 *$ & $1.0 \pm 0.20$ * & $0.63 \pm 0.22^{\star}$ \\
\hline $\begin{array}{l}\text { Forward } \\
\text { elevation(deg) }\end{array}$ & $65.63 \pm 1.82$ & $71.88 \pm 2.41 *$ & $77.81 \pm 2.12^{\star}$ & $95.31 \pm 1.91$ * & $116.3 \pm 2.07 *$ & $138.1 \pm 2.23 *$ \\
\hline $\begin{array}{l}\text { External } \\
\text { rotation (deg) }\end{array}$ & $8.13 \pm 1.36$ & $9.38 \pm 1.93$ & $10.94 \pm 2.1$ & $15 \pm 2.19 *$ & $27.81 \pm 2.28 *$ & $33.44 \pm 2.53^{*}$ \\
\hline $\begin{array}{l}\text { Abduction } \\
\text { (deg) }\end{array}$ & $48.13 \pm 2.09$ & $50.63 \pm 2.66$ & $56.88 \pm 3.38^{*}$ & $82.5 \pm 3.10 *$ & $108.8 \pm 3.52^{*}$ & $138.8 \pm 2.72^{\star}$ \\
\hline $\begin{array}{l}\text { Internal } \\
\text { rotation }\end{array}$ & $17.56 \pm 0.16$ & $17.44 \pm 0.16$ & $17.19 \pm 0.16$ & $16.81 \pm 0.21$ * & $15.19 \pm 0.23^{\star}$ & $13.31 \pm 0.25^{\star}$ \\
\hline ASES & $38.69 \pm 2.03$ & $40.13 \pm 2.05$ & $43.56 \pm 1.93^{*}$ & $58.69 \pm 1.82^{\star}$ & $74.44 \pm 1.98^{*}$ & $89.81 \pm 1.69 *$ \\
\hline UCLA & $9.94 \pm 0.52$ & $10.19 \pm 0.65$ & $11.5 \pm 0.44^{\star}$ & $14.69 \pm 0.51 *$ & $22.25 \pm 0.64^{\star}$ & $29.75 \pm 0.90$ * \\
\hline
\end{tabular}

\section{Discussion}

The greater tuberosity of the humerus is the bony protrusion of the proximal lateral part of the humerus. It is the insertion point of the supraspinatus, subaspinatus and teres minor tendons. After the fracture of the greater tuberosity of the humerus, the fracture block is often displaced posteriorly and upward by the muscle pull, which easily causes acromial impingement syndrome and is often accompanied by rotator cuff injury. If the fracture is not properly reduced, the supraspinatus, subaspinatus or teres minor may be shortened. Muscle strength may also be weakened, which seriously affects the function of the shoulder joint [19]. In addition, the biomechanical test [20] showed that the deltoid force required for abduction of the shoulder joint increased from 116-127\% when the greater tubercle fracture was displaced by $5-10 \mathrm{~mm}$. While the abductive force increased by $29 \%$ when the fragment was displaced by $>1 \mathrm{~cm}$, active surgical treatment should be used for humeral greater tubercle fractures with displacement over $5 \mathrm{~mm}$. Hence, for the patients in this study, the average displacement of fracture blocks was $19.75 \pm 2.05 \mathrm{~mm}(5-30 \mathrm{~mm})$, and only surgical treatment could provide adequate fixation and accurate reduction of the fracture block, which is conducive to the recovery of normal anatomical structure and promotes the rapid recovery of shoulder joint function.

When selecting the optimal surgical fixation strategy for fractures of the greater tuberosity of the humerus, the deforming force caused by rotator cuff muscle elongation should be taken into account. The supraspinatus, infraspinatus and teres minor are inserted into the greater tuberosity of the humerus, and their coupling force plays a crucial role in the function of the shoulder joint. Ogawa et al. [21] reported that most fractures of the greater tubercle of the humerus (57\%) involve the supraspinatus and supraspinatus joints, resulting in upward and backward displacement of the greater tubercle of the humerus in the same direction as the rotator cuff pull for a complete supraspinatus tendon, and note that posterior displacement is particularly important because it is often underestimated and delays treatment. On the other hand, Mutch et al. $[16,22]$ found that $20 \%$ of the fracture blocks of the greater tuberculum shifted downward, and in the study of Bahrs et al. [23], the displacement was up to $25.2 \%$, which suggested that it might be caused by the direct downward force or the impact of the greater tuberculum with the acromion during extreme abduction of the upper limb. In addition, in the case of anterior dislocation of the shoulder, the shear force at the glenoid margin can also lead to greater tuberosity fractures. The suture bridge technique covers the fracture block with the high-strength thread at the end of the anchor, which can effectively disperse the shear force and torsion force of the suture line and obtain satisfactory suture and fixation effects. The network structure formed by the high-strength thread crossing is able to firmly fix the avulsion bone and rotator cuff. Lin et al. [24] reported superior supraspinatus muscle tension on 
the greater tubercle fragment. The fixation of the greater tubercle with an anchor through the rotator cuff was superior to that with two tension screws. The supraspinatus muscle can be reduced by $100 \%$ coverage of the supraspinatus, and the supraspinatus muscle can provide the maximum contact area, which increases the fixation strength of the fracture block and decreases gap formation. The double-row anchor bridge suture technique has been widely used in arthroscopic surgery. Compared with traditional surgical methods, it has certain biomechanical advantages for repairing rotator cuff injuries and fixing fractures of the greater tubercle [15]. Under arthroscopy turned into a double row of anchors, the suture bridge technology with a tail line will smash the humerus fracture piece for complete coverage of the greater tuberosity, provide anatomical repositioning, and anchor the minimally invasive open reduction with fixed line suture bridge technology. This procedure takes the same amount of time of as solid block of fracture fixation, reduces the use of outside anchor nails, saves cost, and reduces the operation steps, thereby shortening the operation time.

Although the bridge suturing technique has obvious advantages in the treatment of greater tubercle fractures of the humerus, arthroscopic surgery itself also has certain limitations, including complicated operations and longer operation times that will increase the potential risk of surgery; surgeons must have a higher learning curve [25]. It has also been reported that arthroscopic double-row anchoring is unlikely to adequately reduce and repair severely displaced fracture fragments and can even damage the rotator cuff [26]. Using minimally invasive open reduction with suture bridge technology can overcome the disadvantages of cancellous bone screw fixation and steel plate internal fixation, reduce the risk of implants fixed weakly or loosely, avoid secondary operations to remove the screw and plate internal fixation and decease the cost compared with arthroscopy. This technique is more beneficial to the good reduction of bone mass and the examination and repair of rotator cuff injury through limited incision and direct vision operations.

Recently, the minimally invasive open reduction and suture technique with suture anchors for the treatment of greater tubercle avulsion fractures of the humerus has achieved good therapeutic results and brought great benefits to patients. The advantages of this technique include: 1) less surgical trauma, fewer postoperative complications, and faster recovery of pain; 2) simple operation, no special equipment, all under direct vision operation; 3) suture anchors are more conducive to the reconstruction of original rotator cuff prints; 4) the suture bridge technique fixes the bone block at rotator cuff insertion on the surface in a multidirectional, overall and stable manner to the humerus head, forming a two-layer plane fixation of rotator cuff insertion, which is accurate and conducive to early functional exercise; 5) suture anchors can form planar multipoint stress fixation, which can disperse the stress, reduce the reduction and loss, and is conducive to the recovery of rotator cuff function; 6) suture anchors are suitable for the treatment of comminuted fracture of greater tuberosity or osteoporotic fracture; and 7) avoids secondary surgery to remove the internal fixation. However, this technique also has several limitations. Due to relatively small fracture fragments, it is difficult for hollow screws to fix avulsion fracture blocks, which are often located above the greater tubercle. The steel plate cannot choose the appropriate location, which leads to more complications and even fixation failure. However, the split fracture block is large, and it is difficult to maintain the stability of the fracture fragment only by suture bridge technology. The compression fracture block is relatively stable, and conservative treatment is generally adopted.

Several notes should be considered when using this technique. 1) When repairing the rotator cuff, the footprint area should be covered by $100 \%$ to provide more contact area while reducing local tension. In addition, the initial fixed strength can be increased to reduce the formation of intertissue space to promote fracture healing and thus enhance the strength of the repaired tendon. 2) For comminuted fracture or small fracture block, fixation with a wire anchor can be used to reduce the possibility of iatrogenic fracture caused by plate fixation. 3) For greater tuberous humeral fracture with a large fracture block, the anchor should be perforated 5-10 $\mathrm{mm}$ from the most lateral edge of the fracture block to prevent the anchor from being too close to the lateral edge of the large fracture block, causing iatric fracture, and to prevent the anchor from failing. 4) The threading position of the anchor suture line should be kept in the same plane, and the suture line should not be inserted between the bone blocks. 5) When the suture is fixed, the tightness should be moderate to maintain a certain tension on the rotator cuff but not be loose and affect healing.

Our study has some limitations. First, this retrospective study had no control group using other fixation techniques, such as locking compression plates or arthroscopic fixation. Second, the sample size was small, with only 16 cases and a follow-up time of no more than 2 years. Therefore, the next step is to continue to accumulate more samples and longer follow-up cases 
and to set up a control group using other treatment methods to evaluate the effect of minimally invasive open reduction and suture bridge techniques for the treatment of humeral greater tubercle fractures.

\section{Conclusion}

This study highlights that minimally invasive open reduction by a modified suture bridge with anchors for avulsion-type greater tuberosity fracture of the humerus yielded an acceptable clinical result, which was fixed firmly and allowed patients early passive shoulder movement postoperatively. It is an efficient and reliable method for the treatment of avulsion-type greater tuberosity fractures of the humerus.

\section{Abbreviations}

VAS: Visual Analogue Scale; ASES: American Shoulder and Elbow surgeons score; UCLA: University of California Los Angeles score; ROM: range of motion; F: Female; M: Man; COPD: Chronic Obstructive Pulmonary Disease; CVA: Cough Variant Asthma; HCV: Hepatitis C Virus; R: Right; L: Life; deg: degree.

\section{Declarations}

\section{Acknowledgements}

The authors thank Dr. Fanxiao Liu (Shandong Provincial Hospital Affiliated to Shandong First Medical University) for his help on this study. The authors also thank AJE company (Durham, North Carolina, USA) for editing the English text of a draft of this manuscript.

\section{Authors' contributions}

LPK and JJY drafted the manuscript, performed data collection and data analysis. YYL conceived of the study and participated in the design of the study. FW performed data interpretation and participated in coordination. All authors read and approved the final manuscript.

\section{Funding}

This article was supported by the Science and Technology Development Program of Shandong Province (No. 2015GSF118110).

\section{Availability of data and materials}

All data analyzed during this study are included in this published article.

\section{Ethics approval and consent to participate}

All experimental procedures were approved by Shandong Provincial Hospital Ethics Committee. All aspects of this study were conducted with adherence to the current version of the Declaration of Helsinki, the guidelines established by the International Conference on Harmonization of Good Clinical Practice, and the laws of China. All participants signed informed consent forms before enrollment.

\section{Consent for publication}

All authors read the final manuscript and approved for publication. 


\section{Competing interests}

The authors declare that they have no competing interests.

\section{Author details}

1 Department of Orthopaedics, Shandong Provincial Hospital Affiliated to Shandong First Medical University, No. 324, Jingwu Road, Jinan 250021, Shandong, P. R. China.

2 Department of Radiotherapy, Shandong Cancer Hospital and Institute, Shandong First Medical University and Shandong Academy of Medical Sciences, Jinan, China.

\section{References}

1. Vijayvargiya M, Pathak A, Gaur S. Outcome Analysis of Locking Plate Fixation in Proximal Humerus Fracture. J Clin Diagn Res. 2016;10(8):RC01-RC5.

2. Kim DR, Noh YM, Lee SY. Arthroscopic Reduction and Suture Bridge Fixation of a Large Displaced Greater Tuberosity Fracture of the Humerus. Arthrosc Tech. 2019;8(9):e975-e85.

3. Rouleau DM, Mutch J, Laflamme GY. Surgical Treatment of Displaced Greater Tuberosity Fractures of the Humerus. J Am Acad Orthop Surg. 2016;24(1): 46-56.

4. Chen YF, Zhang W, Chen Q, Wei HF, Wang L, Zhang CQ. AO X-shaped midfoot locking plate to treat displaced isolated greater tuberosity fractures. Orthopedics. 2013;36(8):e995-e9.

5. White EA, Skalski MR, Patel DB, Gross JS, Tomasian A, Heckmann N, et al. Isolated greater tuberosity fractures of the proximal humerus: anatomy, injury patterns, multimodality imaging, and approach to management. Emerg Radiol. 2018;25(3):235-246.

6. Yin B, Moen TC, Thompson SA, Bigliani LU, Ahmad CS, Levine WN. Operative treatment of isolated greater tuberosity fractures: retrospective review of clinical and functional outcomes. Orthopedics. 2012;35(6):e807-e14.

7. Alberio RL, Del Re M, Grassi FA. Minimally Invasive Plate Osteosynthesis for Proximal Humerus Fractures: A Retrospective Study Describing Principles and Advantages of the Technique. Adv Orthop. 2018:5904028.

8. George MS. Fractures of the greater tuberosity of the humerus. J Am Acad Orthop Surg. 2007;15(10):607-13.

9. Augat P, von Rüden C. Evolution of fracture treatment with bone plates. Injury. 2018;49(Suppl 1):S2-S7.

10. Thanasas C, Kontakis G, Angoules A, Limb D, Giannoudis P. Treatment of proximal humerus fractures with locking plates: a systematic review. J Shoulder Elbow Surg. 2009;18(6):837-44.

11. Kavuri V, Bowden B, Kumar N, Cerynik D. Complications Associated with Locking Plate of Proximal Humerus Fractures. Indian J Orthop. 2018;52(2):108-16.

12. Panagiotopoulou VC, Varga P, Richards RG, Gueorguiev B, Giannoudis PV. Late screw-related complications in locking plating of proximal humerus fractures: A systematic review. Injury. 2019;50(12):2176-95.

13. Yoon TH, Choi CH, Choi YR, Oh JT, Chun YM. Clinical outcomes of minimally invasive open reduction and internal fixation by screw and washer for displaced greater tuberosity fracture of the humerus. J Shoulder Elbow Surg. 2018;27(6): e173e177.

14. Green A, Izzi J Jr. Isolated fractures of the greater tuberosity of the proximal humerus. J Shoulder Elbow Surg. 2003;12(6):641-9.

15. Ji JH, Shafi M, Song IS, Kim YY, McFarland EG, Moon CY. Arthroscopic fixation technique for comminuted, displaced greater tuberosity fracture. Arthroscopy. 2010;26(5):600-9.

16. Mutch J, Laflamme GY, Hagemeister N, Cikes A, Rouleau DM. A new morphological classification for greater tuberosity fractures of the proximal humerus: validation and clinical implications. Bone Joint J. 2014;96-B(5):646-51. 
17. Kim SJ, Choi YR, Lee HH, Chun YM. Surgical Results of Delaminated Rotator Cuff Repair Using Suture-Bridge Technique With All-Layers or Bursal Layer-Only Repair. Am J Sports Med. 2016 Feb;44(2):468-73.

18. Park JS, Park HJ, Kim SH, Oh JH. Prognostic Factors Affecting Rotator Cuff Healing After Arthroscopic Repair in Small to Medium-sized Tears. Am J Sports Med. 2015; 43(10):2386-92.

19. Boileau P, Krishnan SG, Tinsi L, Walch G, Coste JS, Molé D. Tuberosity malposition and migration: reasons for poor outcomes after hemiarthroplasty for displaced fractures of the proximal humerus. J Shoulder Elbow Surg. 2002;11(5):40112.

20. George MS. Fractures of the greater tuberosity of the humerus. J Am Acad Orthop Surg. 2007;15(10):607-13.

21. Ogawa $\mathrm{K}$, Yoshida A, Ikegami $\mathrm{H}$. Isolated fractures of the greater tuberosity of the humerus: solutions to recognizing a frequently overlooked fracture. J Trauma. 2003;54(4):713-7.

22. Mutch JA, Rouleau DM, Laflamme GY, Hagemeister N. Accurate Measurement of Greater Tuberosity Displacement Without Computed Tomography: Validation of a Method on Plain Radiography to Guide Surgical Treatment [published correction appears in J Orthop Trauma. J Orthop Trauma. 2014;28(8):445-51.

23. Bahrs $C$, Lingenfelter E, Fischer F, Walters EM, Schnabel M. Mechanism of injury and morphology of the greater tuberosity fracture. J Shoulder Elbow Surg. 2006;15(2):140-7.

24. Lin CL, Hong CK, Jou IM, Lin CJ, Su FC, Su WR. Suture anchor versus screw fixation for greater tuberosity fractures of the humerus-a biomechanical study. J Orthop Res. 2012;30(3):423-8.

25. Lee SU, Jeong C, Park IJ. Arthroscopic fixation of displaced greater tuberosity fracture of the proximal humerus. Knee Surg Sports Traumatol Arthrosc. 2012 20(2):378-80.

26. Bhatia DN, van Rooyen KS, du Toit DF, de Beer JF. Surgical treatment of comminuted, displaced fractures of the greater tuberosity of the proximal humerus: a new technique of double-row suture-anchor fixation and long-term results. Injury. 2006;37(10):946-52.

\section{Figures}


A

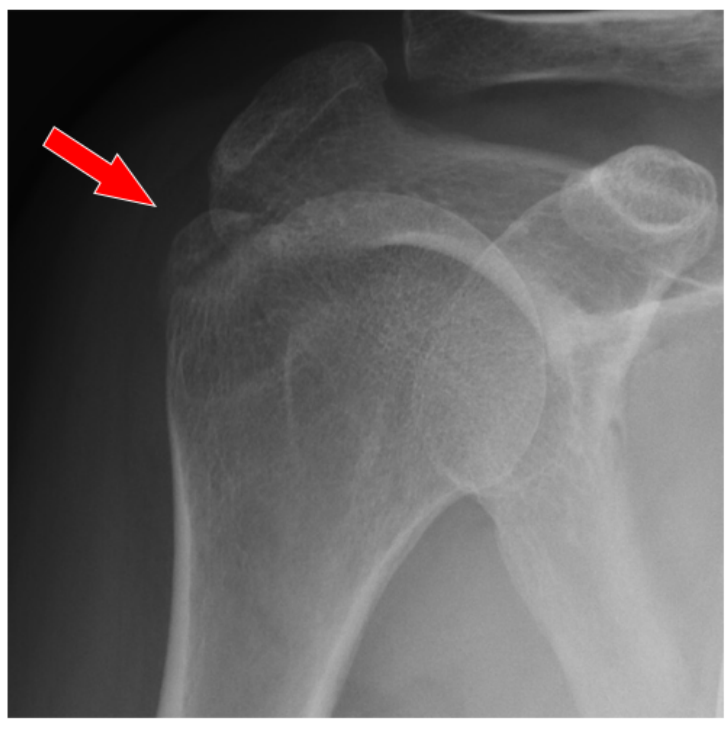

\section{C}

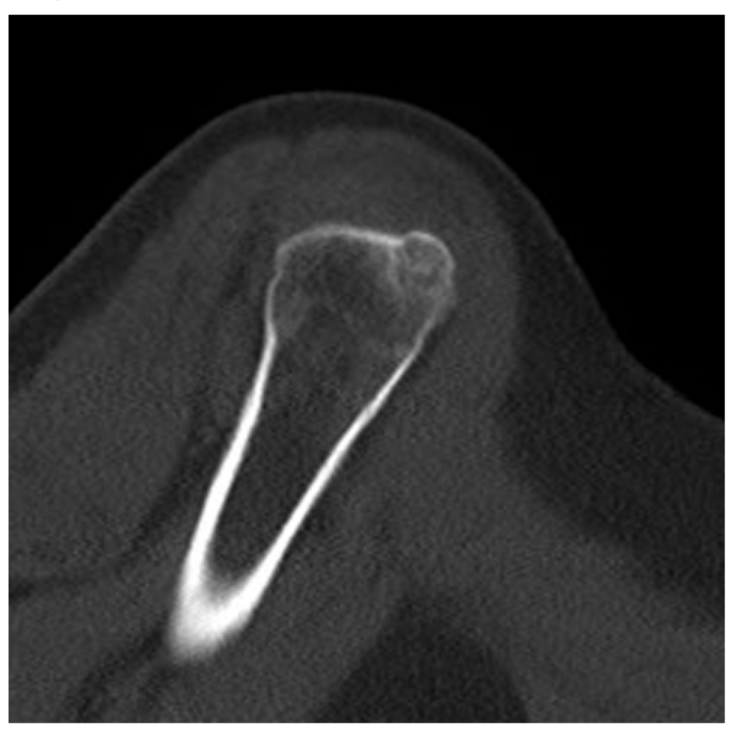

B

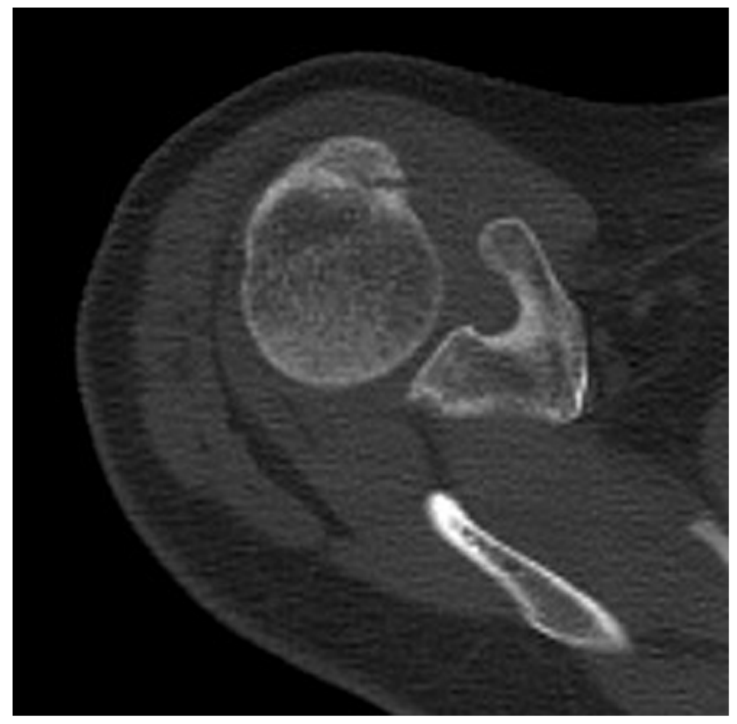

D

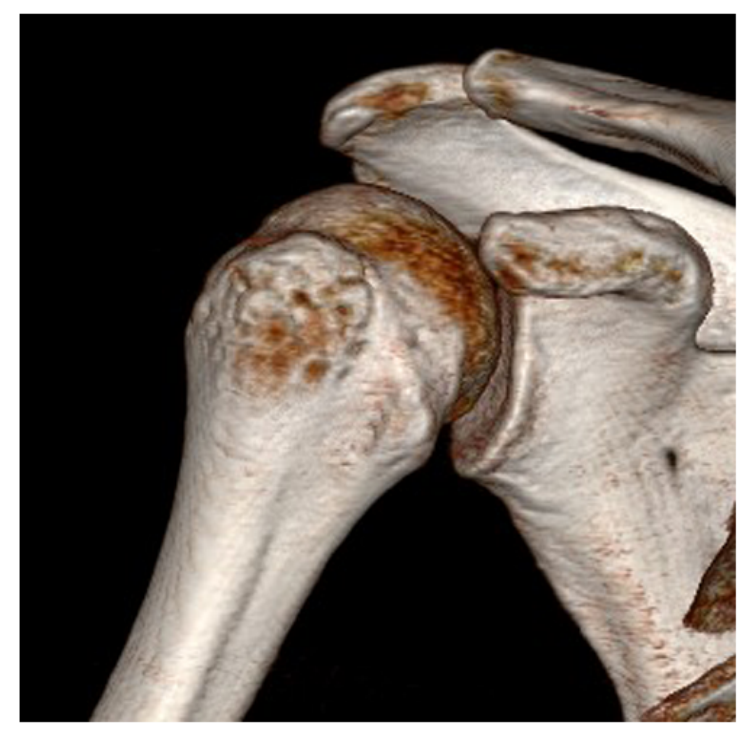

\section{Figure 1}

Imaging examination showed significant displacement of the fracture block of the humeral greater tubercle of the patient. A) Shoulder joint X-ray orthotopic film; B) planar CT scan, C) coronal CT scan, D) three-dimensional reconstruction image of the humerus. 
A

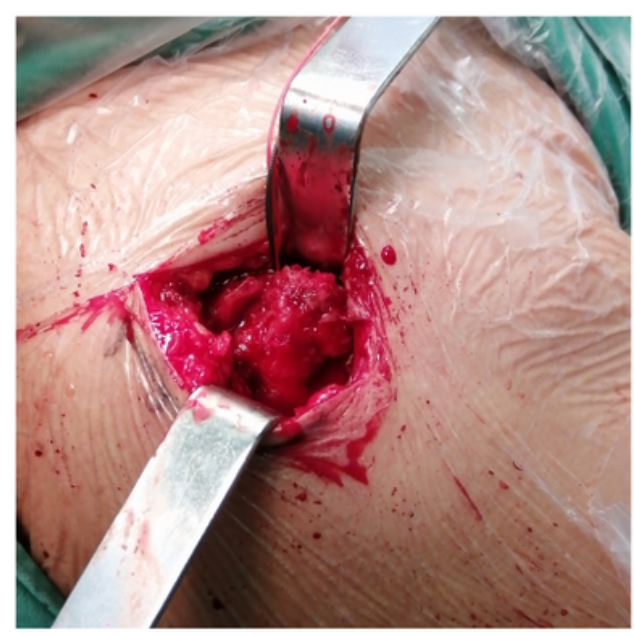

B

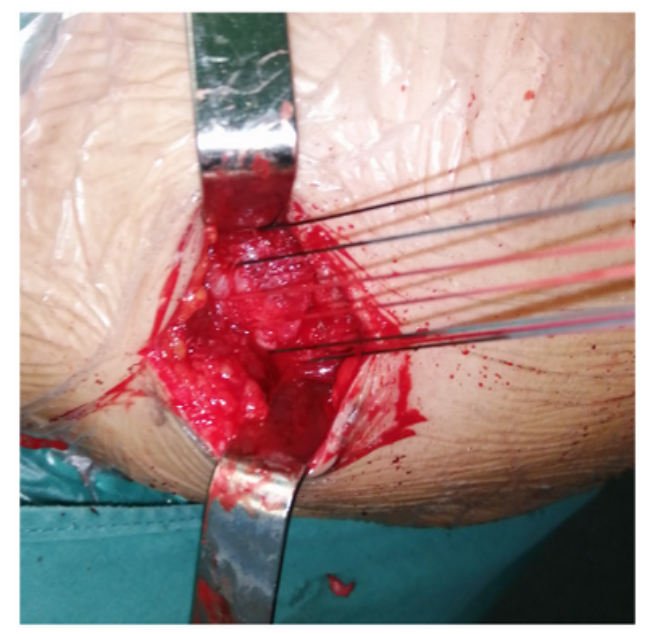

$\mathrm{C}$

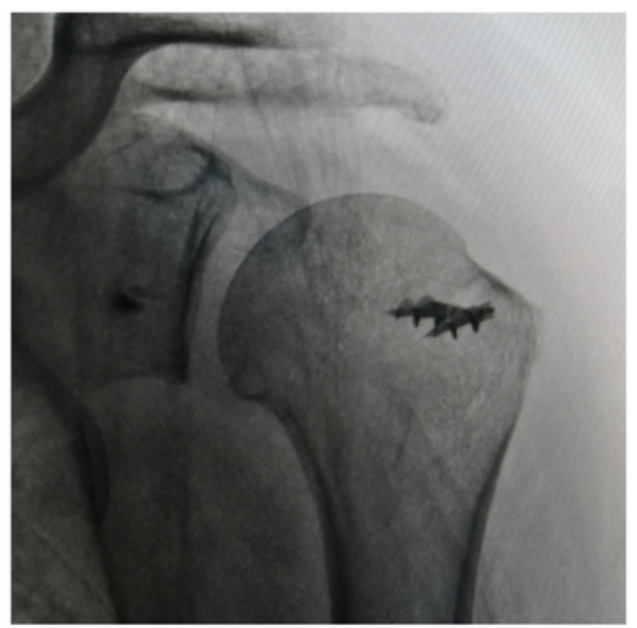

\section{Figure 2}

Intraoperative operation and perspective. A) Avulsion fracture of supraspinatus and infraspinatus stopper, greater tubercle fracture, multiple fracture fragments, rotator cuff tear. B) The anchor lines were passed through the rotator cuff tissue and knotted. C) Intraoperative fluoroscopy showed a good reduction of the fracture block.
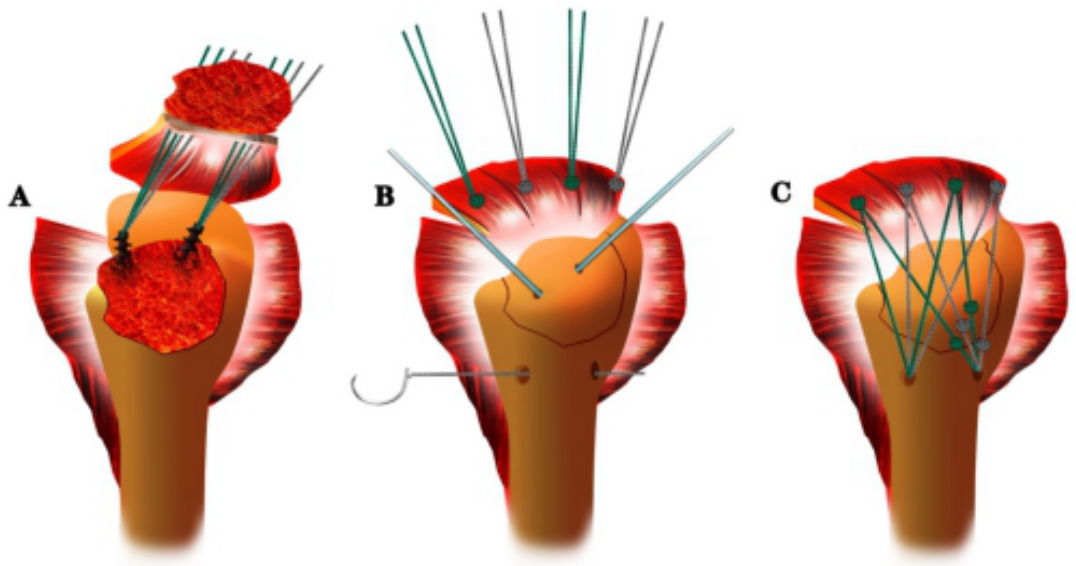

\section{Figure 3}

A schematic diagram of the operation process. A) Two $5.0 \mathrm{~mm}$ anchors were inserted into the cartilaginous margin of the humeral head, and then the anchor lines were threaded through the rotator cuff tissue. B) Kirschner wire was used for temporary fixation of the greater tubercle, and a hole of appropriate length was drilled at the distal outer edge of the fracture line at approximately 5-10 mm, according to the size of the fracture block. C) The greater tubercle fracture block was reduced and fixed by the suture bridge technique to repair the torn rotator cuff tissue (because there should not be too many knots, the number of threads should be used according to the size of the fracture fragment. Generally, 3 threads can be firmly fixed for avulsion greater tubercle fracture of the humerus). 

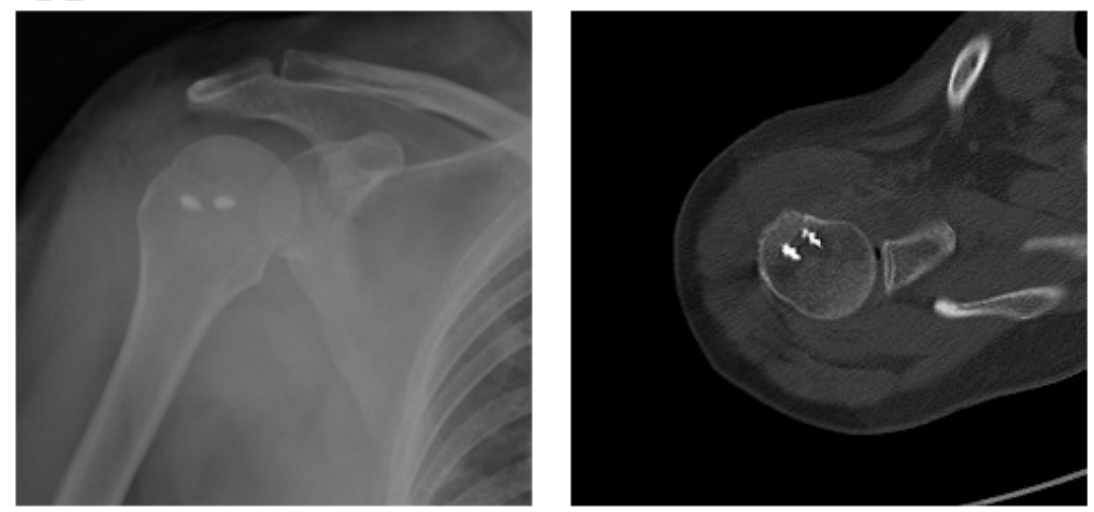

\section{C}

\section{$\mathrm{D}$}
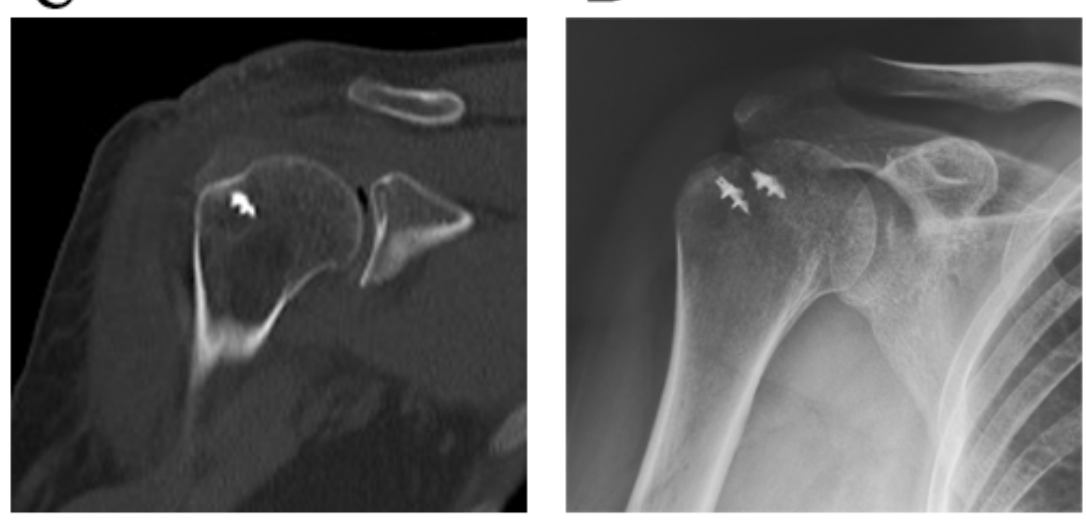

\section{Figure 4}

Postoperative radiograph and CT showing good reduction of the greater tuberosity. Fracture block alignment was good 1 day after surgery, A) shoulder joint X-ray orthotopic film; B) planar CT scan; C) coronal CT scan. D) The patient achieved bone union 1 months after surgery. 